\title{
PENENTUAN FAKTOR-FAKTOR YANG MEMPENGARUHI KESEJAHTERAAN MASYARAKAT DALAM BIDANG PENDIDIKAN DENGAN MENGGUNAKAN REGRESI MULTIVARIAT (STUDI KASUS: [PENDIDIKAN DI KABUPATEN DAN KOTA DI PROPINSI SUMATERA BARAT
}

\author{
ZIKALTA PUTRA, HAZMIRA YOZZA, IZZATI RAHMI HG \\ Program Studi Matematika, \\ Fakultas Matematika dan Ilmu Pengetahuan Alam, Universitas Andalas, \\ Kampus UNAND Limau Manis Padang, Indonesia, \\ putrazil@yahoo.com
}

\begin{abstract}
Abstrak. Pendidikan merupakan salah satu aspek penting dalam meningkatkan kesejahteraan penduduk. Terdapat beberapa indikator kesejahteraan penduduk dalam bidang pendidikan dua diantaranya adalah angka melek huruf dan angka partisipasi sekolah yang terbagi menjadi kelompok umur $13--15,16--18$, dan $19--24$. Berdasarkan nilai AICc yang diperoleh pada analisis regresi multivariat faktor-faktor yang berpengaruh terhadap indikator kesejahteraan pendidikan tersebut adalah jumlah sekolah SD/sederajat, rasio guru dan murid SMP/sederajat, kepadatan penduduk, persentase penduduk miskin dan PDRB perkapita. Berdasarkan kriteria eta square lambda, variabel-variabel tersebut dapat menjelaskan informasi dalam model regresi multivariat sebesar 94,55
\end{abstract}

Kata Kunci: Pendidikan, angka melek huruf, angka partisipasi sekolah, analisis regresi multivariat, $A I C C$

\section{Pendahuluan}

Pendidikan merupakan hal yang terpenting dalam kehidupan kita. Setiap manusia berhak mendapat dan berharap untuk selalu berkembang dalam pendidikan. Menurut UUD 1945 pasal 27, pendidikan adalah hak setiap warga negara, sehingga seluruh masyarakat berhak untuk mendapatkan pendidikan yang layak. Semakin tinggi tingkat pendidikan suatu bangsa, akan semakin majulah bangsa tersebut. Pendidikan merupakan salah satu aspek penting dalam meningkatkan kesejahteraan penduduk. Terdapat beberapa indikator kesejahteraan penduduk dalam bidang pendidikan dua diantaranya adalah angka melek huruf dan angka partisipasi sekolah. Angka melek huruf digunakan untuk mengukur keberhasilan program pemberantasan buta huruf, sedangkan angka partisipasi sekolah merupakan indikator yang mengukur pemerataan akses terhadap pendidikan, baik di tingkat pendidikan dasar maupun di tingkat pendidikan menengah.

Berdasarkan data yang dihimpun oleh The Hidden Crisis, Armed Conflict and Education yang dikeluarkan Organisasi Pendidikan, Ilmu Pengetahuan, dan Kebudayaan Perserikatan Bangsa-Bangsa (UNESCO) dan dilaporkan dalam dalam 
Education For All (EFA) Global Monitoring Report 2012, indeks pembangunan pendidikan atau Education Development Index (EDI) Indonesia yang dihitung berdasarkan data tahun 2008 adalah 0.934 . Nilai tersebut menempatkan Indonesia dalam kategori negara dengan EDI medium. Meskipun demikian, nilai tersebut hanya menempatkan Indonesia pada posisi 69 dari 127 negara. Ini berarti bahwa dibandingkan dengan negara-negara lain di dunia, sesungguhnya Indonesia tertinggal jauh dalam hal indeks pembangunan pendidikan.

Berangkat dari permasalahan tersebut, suatu hal yang menarik untuk diteliti adalah faktor-faktor apa saja yang mempengaruhi tingkat kesejahteraan penduduk dalam bidang pendidikan khususnya angka melek huruf dan angka partisipasi sekolah. Jawaban permasalahan tersebut berupa model matematika yang dapat digunakan untuk mengontrol dan memprediksikan variabel-variabel yang perlu diperhatikan untuk menggambarkan tingkat kesejahteraan penduduk dalam bidang pendidikan. Untuk tujuan tersebut, analisis yang dapat dilakukan analisis regresi. Dalam permasalahan ini terdapat lebih dari satu variabel respon dan lebih dari satu variabel prediktor maka analisis regresi yang sesuai adalah analisis regresi multivariat.

\section{Tinjauan Pustaka}

\subsection{Indikator Kesejahteraan Pendidikan}

Peningkatan kesejahteraan penduduk merupakan salah satu tujuan utama dari suatu program perekonomian suatu daerah. Kesejahteraan penduduk dapat dilihat dari beberapa aspek, salah satunya adalah pendidikan. Terdapat beberapa indikator kesejahteraan penduduk dalam bidang pendidikan, dua diantaranya adalah sebagai berikut:

(1) Angka Melek Huruf (persen).

Angka melek huruf merupakan persentase penduduk usia 15 tahun keatas yang dapat membaca dan menulis huruf latin dan atau huruf lainnya serta mengerti sebuah kalimat sederhana dalam kehidupan sehari-hari. Angka ini digunakan untuk mengukur keberhasilan program pemberantasan buta huruf.

(2) Angka Partisipasi Sekolah (persen).

Angka partisipasi sekolah (APS) merupakan salah satu indikator yang digunakan untuk melihat partisipasi penduduk khususnya anak usia sekolah dalam proses kegiatan pendidikan formal. APS juga dapat digunakan untuk melihat tingkat kemampuan lembaga pendidikan formal (sekolah) dalam menyerap warga belajar terutama anak usia sekolah. APS ini dibagi dalam beberapa kelompok umur yaitu APS kelompok umur 13 - 15, APS kelompok umur $16--18$, dan APS kelompok umur $19--24$.

\subsection{Analisis Regresi Multivariat}

Analisis regresi multivariat merupakan analisis regresi yang dilakukan apabila terdapat lebih dari satu variabel respon. Model regresi multivariat adalah model regresi yang terdiri dari lebih dari satu variabel respon dan satu atau lebih variabel-variabel 
prediktor [?]. Jika terdapat variabel respon sebanyak $q$ dan $p$ variabel prediktor maka model regresi multivariat untuk pengamatan ke- $i$ respon ke- $j$ adalah

$Y_{i 1}=\beta_{01}+\beta_{11} x_{i 1}+\beta_{21} x_{i 2}+\ldots+\beta_{p 1} x_{i p}+\varepsilon_{i 1}$

$Y_{i 2}=\beta_{02}+\beta_{12} x_{i 1}+\beta_{22} x_{i 2}+\ldots+\beta_{p 2} x_{i p}+\varepsilon_{i 2}$

$Y_{i q}=\beta_{0 q}+\beta_{1 q} x_{i 1}+\beta_{2 q} x_{i 2}+\ldots+\beta_{p q} x_{i p}+\varepsilon_{i q}$, dengan

$y_{i j}$ : Nilai amatan ke - iuntuk variabel respon ke $-j, i=1,2, \cdots, n, j=1,2, \cdots, q$,

$x_{i k}:$ Nilai amatan ke - iuntuk variabel prediktor ke- $k ; k=1,2, \cdots, p$,

$\beta_{k j}$ : Parameter regresi untuk variabel prediktor ke- $k$ dan variabel respon ke- $j$,

$\varepsilon_{i j}:$ Galat amatan ke-iuntukvariabelresponke- $j$.

Metode regresi multivariat yang terdiri atas $q$ model linear secara simultan dapat ditunjukkan secara matriks dalam persamaan :

$$
Y_{(n \times q)}=X_{n \times(p+1)} \beta_{(p+1) \times q}+\varepsilon_{(n \times q)}
$$

Dalam analisis regresi multivariat ini, asumsi yang harus dipenuhi adalah [?]

$$
\varepsilon \sim \operatorname{MVN}\left(0, \sigma^{2} I\right)
$$

\subsection{Estimasi Parameter}

Model 2.1 dapat diduga dengan model sebagai berikut [6]:

$$
Y_{(n \times q)}=X_{n \times(p+1)} b_{(p+1) \times q}+e_{(n \times q)}
$$

dengan $b^{T}=\left(b_{0}, b_{1},, b_{q}\right)$ adalah nilai dugaan bagi $\beta^{T}=\left(\beta_{0}, \beta_{1},, \beta_{q}\right)$ dan $e^{T}=$ $\left(e_{1}, e_{2}, e_{q}\right)$ adalah vektor sisaan. Nilai $\mathbf{b}$ diperoleh salah satunya dengan menggunakan metode kuadrat terkecil (MKT). Dengan metode ini, b diperoleh dengan meminimumkan jumlah kuadrat sisaan (JKS), sehingga diperoleh pendugaan koefisien regresi sebagai berikut:

$$
\mathbf{b}=\left(\mathbf{X}^{\mathbf{T}} \mathbf{X}\right)^{-1} \mathbf{X}^{\mathbf{T}} \mathbf{Y}
$$

\subsection{Akaike's Information Criterion Corrected (AICc)}

AICc adalah pengembangan dari AIC, dimana AICc ini sangat baik digunakan apabila data memilki ukuran sampel yang kecil. Suatu model dikatakan baik apabila nilai AICc nya paling kecil diantara semua kemungkinan model. Besarnya AICc dapat dihitung sebagai berikut :

$$
A I C c=n(\ln |\widehat{\Sigma}|+q)+\frac{2 d n}{(n-q-p-1)}
$$

dengan :

$$
\begin{aligned}
& q: \text { jumlah variabel respond } p q+0,5 q(q+1), \\
& p: \text { jumlah variabel prediktor } \\
& \widehat{\Sigma}: \text { penaksir matriks varian kovarian galat, } \\
& n: \text { jumlah pengamatan. }
\end{aligned}
$$




\section{Metode Penelitian}

\subsection{Sumber Data}

Data yang digunakan pada penelitian ini diperoleh dari Sumatera Barat Dalam Angka Tahun 2014 yang diterbitkan oleh BPS. Data ini merupakan data hasil survey yang dilakukan pada tahun 2013 oleh BPS (Badan Pusat Statistik) dan BAPPEDA (Badan Pembangunan Daerah) Provinsi Sumatera Barat.

\subsection{Variabel Penelitian}

(1) Variabel respon yang digunakan pada penelitian ini adalah $Y_{1}=$ Angka Melek Huruf (persen)

$Y_{2}=$ Angka partisipasi sekolah kelompok umur 13 - 15 (persen)

$Y_{3}=$ Angka partisipasi sekolah kelompok umur 16 - 18 (persen)

$Y_{4}=$ Angka partisipasi sekolah kelompok umur 19 - 24 (persen)

(2) Variabel prediktor yang digunakan pada penelitian ini adalah $X_{1}$ : Jumlah Sekolah SMP/Sederajat

$X_{2}$ : Jumlah Sekolah SMA/Sederajat $X_{3}$ : Jumlah Sekolah SD/Sederajat

$X_{4}$ : Rasio Guru dan Murid Pada Jenjang SD/Sederajat

$X_{5}$ : Rasio Guru dan Murid Pada Jenjang SMP/Sederajat

$X_{6}$ : Rasio Guru dan Murid Pada Jenjang SMA/Sederajat

$X_{7}$ : Kepadatan Penduduk

$X_{8}$ : Tingkat Partisipasi Angkatan Kerja

$X_{9}$ : Persentase Penduduk Miskin

$X_{10}:$ PDRB/Perkapita

$X_{11}$ : Pendapatan Asli Daerah

\subsection{Metode Analisis Data}

Adapun langkah-langkah analisis yang akan dilakukan dalam penelitian ini adalah

(1) Membuat statistik deskriptif variabel respon dan variabel prediktor untuk mengetahui gambaran umum data.

(2) Menguji korelasi antar variabel respon apabila terdapat korelasi antar variabel respon maka dilanjutkan dengan analisis regresi multivariat.

(3) Melakukan analisis regresi multivariat, dengan langkah-langkah sebagai berikut:

(a) Melakukan pemilihan model dengan AICc.

(b) Melakukan estimasi parameter model regresi.

(c) Melakukan pengujian signifikansi parameter model regresi multivariat.

(d) Melakukan pengujian kesamaan matriks ragam peragam galat, kebebasan galat dan kenormalan galat.

(e) Mendapatkan faktor-faktor yang berpengaruh terhadap tingkat kesejahteraan dalam bidang pendidikan. 


\section{Hasil dan Pembahasan}

\subsection{Gambaran Umum Data}

Pada angka melek huruf, angka melek huruf terendah yaitu sebesar 93,89 persen terjadi pada Kabupaten Kepulauan Mentawai dan yang tertinggi adalah sebesar 99,94 persen terjadi di Kota Bukittinggi. Artinya persentase penduduk yang berusia 15 tahun ketas yang dapat membaca dan menulis di Kabupaten Kepulauan Mentawai masih rendah dibandingkan dengan kota dan kabupaten lainnya di Sumatera Barat. Hal ini harus menjadi perhatian oleh pemerintah setempat dan perlunya diperbaiki faktor yang mempengaruhi persentase ini.

Pada angka partisipasi sekolah (APS) $13--15$ terendah terjadi di Kabupaten Sijunjung yaitu 86,20 persen dan yang tertinggi di Kota Payakumbuh yaitu 98,86 persen. Pada APS 16-18 terendah terdapat pada Kabupaten Kepulauan Mentawai yaitu sebesar 59,03 persen dan tertinggi di Kota Solok sebesar 84,91 persen. Dan pada APS 19 - - 24 terendah terjadi pada Kota Sawahlunto sebesar 13,01 persen dan tertinggi pada Kota Padang yaitu 51,58 persen.

\subsection{Pembentukan Model Regresi Multivariat}

Sebelum dibentuk model regresi multivariat, dilakukan pengujian korelasi antar variabel respon, jika terdapat korelasi antar variabel respon maka dilanjutkan dengan menggunakan regresi multivariat.

\section{Korelasi Antar Variabel Respon}

Tabel 1. Hubungan Antar Variabel Respon

\begin{tabular}{|c|l|c|c|c|}
\hline \multicolumn{2}{|c|}{ Variabel respon } & AMH (Y1) & APS13-15 (Y2) & APS16-18(Y3) \\
\hline \multirow{2}{*}{ APS13-15 (Y2) } & Koefisien korelasi & 0,220 & - & - \\
\cline { 2 - 5 } & Nilai- $p$ & 0,365 & - & - \\
\hline \multirow{2}{*}{ APS16-18(Y3) } & Koefisien korelasi & 0,477 & 0,338 & - \\
\cline { 2 - 5 } & Nilai- $p$ & 0,039 & 0,157 & - \\
\hline \multirow{2}{*}{ APS19-24 (Y4) } & Koefisien korelasi & 0,463 & 0,226 & 0,521 \\
\cline { 2 - 5 } & Nilai- $p$ & 0,046 & 0,352 & 0,022 \\
\hline
\end{tabular}

Dari Tabel 1, terdapat nilai- $p$ dari masing-masing korelasi. Jika ditetapkan nilai $\alpha=0.05, H_{0}$ diterima jika nilai- $p>\alpha=0.05$. Dilihat dari Tabel 1 korelasi antara variabel $Y_{1}$ dengan $Y_{2}, Y_{2}$ dengan $Y_{3}$ dan $Y_{2}$ dengan $Y_{4}$ dapat disimpulkan diterima $H_{1}$. Artinya korelasi antara variabel $Y_{1}$ dengan $Y_{2}, Y_{2}$ dengan $Y_{3}$ dan $Y_{2}$ dengan $Y_{4}$ tidak ada. Korelasi antar variabel respon lainnya disimpulkan bahwa diterimanya $H_{1}$, yang berarti korelasi antar variabel respon tersebut ada.

\section{Pemilihan Model Terbaik}

Pemilihan model terbaik dilakukan dengan menggunakan kriteria AICc. Nilai AICc diperoleh untuk semua kemungkinan model regresi antara variabel respon $Y_{1}, Y_{2}$, 
$Y_{3}$, dan $Y 4$ dengan variabel prediktor $X_{1}, X_{2}, X_{3}, X_{4}, X_{5}, X_{6}, X_{7}, X_{8}, X_{9}, X_{10}$, dan $X_{11}$.

Tabel 2. Nilai AICc untuk Pemilihan Model Terbaik

\begin{tabular}{|l|l|l|l|l|l|}
\hline No & Prediktor & AICc & No & Prediktor & AICc \\
\hline 1 & $\mathrm{X}_{7}$ & 321,2437 & 11 & $\mathrm{X}_{1} \mathrm{X}_{2} \mathrm{X}_{5} \mathrm{X}_{6} \mathrm{X}_{9} \mathrm{X}_{10}$ & 305,8026 \\
\hline 2 & $\mathrm{X}_{9}$ & 321,4799 & 12 & $\mathrm{X}_{1} \mathrm{X}_{2} \mathrm{X}_{5} \mathrm{X}_{7} \mathrm{X}_{9} \mathrm{X}_{10}$ & 302,3396 \\
\hline 3 & $\mathrm{X}_{7} \mathrm{X}_{9}$ & 313,0515 & 13 & $\mathrm{X}_{1} \mathrm{X}_{2} \mathrm{X}_{3} \mathrm{X}_{5} \mathrm{X}_{7} \mathrm{X}_{9} \mathrm{X}_{10}$ & 306,5482 \\
\hline 4 & $\mathrm{X}_{9} \mathrm{X}_{10}$ & 312,5151 & 14 & $\mathrm{X}_{1} \mathrm{X}_{2} \mathrm{X}_{5} \mathrm{X}_{6} \mathrm{X}_{7} \mathrm{X}_{9} \mathrm{X}_{10}$ & 305,8213 \\
\hline 5 & $\mathrm{X}_{7} \mathrm{X}_{9} \mathrm{X}_{10}$ & 306,2494 & 15 & $\mathrm{X}_{1} \mathrm{X}_{2} \mathrm{X}_{3} \mathrm{X}_{4} \mathrm{X}_{7} \mathrm{X}_{8} \mathrm{X}_{9} \mathrm{X}_{10}$ & 313,2492 \\
\hline 6 & $\mathrm{X}_{7} \mathrm{X}_{9} \mathrm{X}_{11}$ & 308,6670 & 16 & $\mathrm{X}_{1} \mathrm{X}_{2} \mathrm{X}_{3} \mathrm{X}_{5} \mathrm{X}_{7} \mathrm{X}_{8} \mathrm{X}_{9} \mathrm{X}_{10}$ & 310,6451 \\
\hline 7 & $\mathrm{X}_{7} \mathrm{X}_{8} \mathrm{X}_{9} \mathrm{X}_{10}$ & 308,5081 & 17 & $\mathrm{X}_{1} \mathrm{X}_{2} \mathrm{X}_{3} \mathrm{X}_{4} \mathrm{X}_{5} \mathrm{X}_{6} \mathrm{X}_{7} \mathrm{X}_{9} \mathrm{X}_{10}$ & 320,0015 \\
\hline 8 & $\mathrm{X}_{7} \mathrm{X}_{9} \mathrm{X}_{10} \mathrm{X}_{11}$ & 306,9939 & 18 & $\mathrm{X}_{1} \mathrm{X}_{2} \mathrm{X}_{3} \mathrm{X}_{4} \mathrm{X}_{5} \mathrm{X}_{7} \mathrm{X}_{8} \mathrm{X}_{9} \mathrm{X}_{10}$ & 319,5404 \\
\hline 9 & $\mathrm{X}_{3} \mathrm{X}_{5} \mathrm{X}_{7} \mathrm{X}_{9} \mathrm{X}_{10}$ & $\mathbf{3 0 2 , 2 5 8 6}$ & 19 & $\mathrm{X}_{1} \mathrm{X}_{2} \mathrm{X}_{3} \mathrm{X}_{4} \mathrm{X}_{5} \mathrm{X}_{6} \mathrm{X}_{7} \mathrm{X}_{8} \mathrm{X}_{9} \mathrm{X}_{10}$ & 333,8770 \\
\hline 10 & $\mathrm{X}_{6} \mathrm{X}_{7} \mathrm{X}_{9} \mathrm{X}_{10} \mathrm{X}_{11}$ & 306,6881 & 20 & $\mathrm{X}_{1} \mathrm{X}_{2} \mathrm{X}_{3} \mathrm{X}_{4} \mathrm{X}_{5} \mathrm{X}_{6} \mathrm{X}_{7} \mathrm{X}_{8} \mathrm{X}_{9} \mathrm{X}_{10} \mathrm{X}_{11}$ & 445,6772 \\
\hline
\end{tabular}

Keterangan. Nilai AICc yang ditampilkan adalah nilai AICc terbaik dari semua model regresi yang terbentuk

Berdasarkan kriteria pemilihan model terbaik dengan menggunakan AICc model yang baik adalah model yang memiliki nilai AICc terkecil. Dari tabel tersebut terlihat bahwa nilai AICc terkecil adalah 302,2586 yaitu model dengan variabel prediktor jumlah sekolah $\mathrm{SD} /$ sederajat $\left(X_{3}\right)$, rasio murid dan guru $\operatorname{SMP} /$ sederajat $\left(X_{5}\right)$, kepadatan penduduk $\left(X_{7}\right)$, persentase penduduk miskin $\left(X_{9}\right)$, PDRB/perkapita $\left(X_{10}\right)$. Oleh karena itu, model yang terbaik berdasarkan kriteria tersebut adalah model yang mengandung kelima variabel prediktor tersebut.

\section{Estimasi Parameter Regresi Multivariat}

Setelah diperoleh variabel prediktor yang akan masuk kedalam model, maka langkah selanjutnya adalah membentuk model regresi multivariat. Persamaan model regresi multivariat yang terbentuk adalah sebagai berikut :

$$
\begin{aligned}
& Y_{i 1}=99,4+0,00049 X_{i 3}+0,133 X_{i 5}+0,000400 X_{i 7}-0,406 X_{i 9}+0,0014 X_{i 10} \\
& Y_{i 2}=89,4-0,00061 X_{i 3}-0,195 X_{i 5}-0,00004 X_{i 7}+0,096 X_{i 9}+0,166 X_{i 10} \\
& Y_{i 3}=76,3+0,0194 X_{i 3}+2,26 X_{i 5}+0,00263 X_{i 7}-1,84 X_{i 9}-0,591 X_{i 10} \\
& Y_{i 4}=0,2+0,0165 X_{i 3}+1,17 X_{i 5}+0,00538 X_{i 7}-0,504 X_{i 9}+0,567 X_{i 10} .
\end{aligned}
$$

Tingkat keeratan hubungan antara variabel respon dan variabel prediktor diketahui berdasarkan Eta Square Lambda sehingga diperoleh nilai $\eta_{\wedge}^{2}=1-\wedge=1$ $0,054478066=0,945521934$. Ini dapat dikatakan bahwa model tersebut dapat menjelaskan informasi data sebesar 94,55 persen sehingga semua variabel terpilih dapat dijadikan faktor untuk mengukur angka melek huruf dan angka partisipasi sekolah, yang merupakan indikator kesejahteraan masyarakat dalam bidang pendidikan.

\section{Pengujian Signifikansi Model}


Pengujian parameter berhubungan dengan signifikansi model yang diuji secara serentak dan parsial. Dalam pengujian signifikansi model secara serentak digunakan uji wilks lambda. Didapatkan $\wedge=0,054478066$ dan $V_{\text {hitung }}=37,8294$ dan dengan taraf nyata $\alpha=0,05$ diperoleh $X_{v=p q}^{2}=31,4$. Karena $V_{\text {hitung }}=37,8294>31,4$ maka kesimpulannya adalah tolak $H_{0}$ yang berarti secara serentak, paling tidak ada satu variabel prediktor yang signifikan berpengaruh terhadap model. Dari pengujian secara parsial disajikan pada tabel berikut:

Tabel 3. Tabel Uji Parsial (Nilai Kritis $X_{4}^{2}=9.49$ )

\begin{tabular}{|c|c|c|c|}
\hline No & Prediktor & $\Lambda_{\text {hitung }}$ & $V$ \\
\hline 1 & $X_{3}$ & 0,92577737 & 1,1400185 \\
\hline 2 & $X_{5}$ & 0,44667811 & 12,071952 \\
\hline 3 & $X_{7}$ & 0,80727003 & 3,1945596 \\
\hline 4 & $X_{9}$ & 0,45225247 & 11,885917 \\
\hline 5 & $X_{10}$ & 0,49009286 & 10,680602 \\
\hline
\end{tabular}

\section{Pengujian Asumsi}

Pada pengujian asumsi kesamaan matriks ragam peragam diperoleh yaitu $X_{\text {hitung }}^{2}=9,27$ lebih kecil dari $X_{\text {tabel }}^{2}=X_{(0.05,1 / 2(2-1) 4(4+1))}^{2}=18,3$, maka diputuskan untuk tidak tolak $H_{0}$, yang berarti matriks ragam peragam galat adalah homogen. Pada pengujian asumsi kebebasan galat diperoleh hasil yaitu $X_{\text {hitung }}^{2}=12,16$ kurang dari $X_{\text {tabel }}^{2}=12,59$ sehingga disimpulkan bahwa $H_{0}$ diterima. Ini berarti matriks galat dari model yang terpilih membentuk matriks identitas atau dapat dikatakan bahwa galat bersifat saling bebas. Dan pada pengujian asumsi kenormalan galat diperoleh kondisi $d_{i}^{2}<3,36$ terhadap 10 pengamatan atau 52,63 persen dari 19 pengamatan, maka disimpulkan H0 diterima. Artinya galat terdistribusi normal multivariat.

\section{Kesimpulan dan Saran}

\subsection{Kesimpulan}

Dari pemodelan hubungan antara variabel respon dengan semua variabel prediktor diketahui bahwa jumlah sekolah $\mathrm{SD} /$ sederajat, rasio guru dan murid SMP/sederajat, kepadatan penduduk, persentase penduduk miskin dan PDRB perkapita dapat dijadikan indikator untuk memprediksikan angka melek huruf, APS 13-15, APS 16-18, dan APS 19-24. Variabel-variabel tersebut dapat menjelaskan informasi dalam model regresi multivariat sebesar 94,55 persen.

\subsection{Saran}

Untuk pemerintah lebih difokuskan pada pengurangan persentase penduduk miskin untuk meningkatkan angka melek huruf dan angka partisipasi sekolah secara keseluruhan di Kabupaten dan Kota di Sumatera Barat. Untuk penelitian selanjut- 
nya dapat digunakan faktor-faktor lain yang berpengaruh dengan tidak melepaskan faktor-faktor yang berpengaruh.

\section{Daftar Pustaka}

[1] Badan Perencanaan Pembangunan Nasional. 2009. Evaluasi Pelaksanaan Program Wajib Belajar Pendidikan Dasar 9 Tahun. Jakarta(ID) : BPPN.

[2] Badan Pusat Statistik Sumatera Barat. (2011). Indikator Kesejahteraan Rakyat Sumatera Barat. Badan Pusat Statistik Provinsi Sumatera Barat. Padang.

[3] Badan Pusat Statistik Indonesia. (2014). Angka Melek Huruf Dan Angka Partisipasi Sekolah Menurut Provinsi 2003-2013. Badan Pusat Statistik Indonesia.

[4] Badan Pusat Statistik Sumatera Barat. (2007). Indikator Pembangunan Pendidikan. Badan Pusat Statistik Provinsi Sumatera Barat. Padang.

[5] Cavanaugh, J. E, (1997), Unifiying The Derivations For The Akaike And Corected Akaike Information Criteria. Department of Statistics, University of Missouri, Columbia. http://myweb.uiwoa.edu./diakses pada tanggal 5 Mei 2015.

[6] Draper, N. dan Smith.1992. Analisis Regresi Terapan, Edisi kedua, PT. Gramedia Pustaka Utama, Jakarta.

[7] Gaspers, Vincent. 1992. Teknik Analisis Dalam Penelitian Percobaan. Tarsito, Bandung

[8] Johnson, R. A. dan D. W. Wichern. (1992). Applied Multivariate Statistical Analysis, Third Edition .New Jersey : Practice Hall.

[9] Morrison, D. F. (2005). Multivariate Statistical Methods, Fourth Edition. Pennsylvania: The Warton School University of Pennsylvania.

[10] Tabachnick, B. G dan L. S. Fidell. (2013). Using Multivariate Statistics. Sixth Edition. California State University, Northridge. 